\title{
Trabajo Social de siglo XXI. Una crítica al discurso brasileños et alii'
}

\author{
O Serviço Social do século XXI. Uma crítica \\ ao discurso brasileños et alii
}

\section{Social Work in the $21^{\text {st }}$ Century. A criticism of the discourse of brasileños et alii}

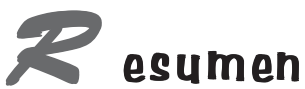

La comunicación tiene el propósito de compartir una pluralidad de reflexiones, si bien detonadas por la convocatoria al LIII Congreso de la Asociación Mexicana de Escuelas de Trabajo Social, fundamentalmente suscitadas por la investigación epistemológica del autor. De innegable sentido psicoanalítico y ético-geopolítico, gira en torno a preguntas no-dogmáticas que procuran servir de brújulas intelectuales, la principal de las cuales nos refiere a las competencias que los pueblos-naciones de nuestra América están demandándole a los trabajadores sociales y a las trabajadoras sociales. A lo largo de los cuatro apartados, el autor configura un campo de visión desde el que mira y resignifica el trabajo social y la realidad latinoiberoindoafrocaribeña; asimismo, disemina sus dudas autocríticas sin pretender llegar a conclusiones, mucho menos definitivas, no obstante lo cual se muestra implacable en su crítica a "La" reconceptualización y sus vinculaciones con la neomoderna ortodoxia marxista que el autor denomina brasileños et alii.

Palabras clave: competencias profesionales, trabajosocionomía, neoposglo, eclecticismo.

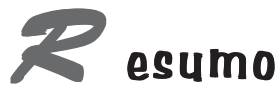

Esta comunicação tem o propósito de compartilhar uma pluralidade de reflexões, embora deflagradas pela convocação ao LIII Congresso da Associação Mexicana de Escolas de Serviço Social, fundamentalmente suscitadas pela investigação epistemológica do autor. De inegável sentido psicanalítico e ético-geopolítico, gira em torno de perguntas não-dogmáticas que procuram servir de bússolas intelectuais; a principal delas remete às competências que os povos-nações de nossa América estão demandando aos assistentes sociais. Ao longo das quatro seções que compõem o artigo, o autor configura um campo de visão a partir do qual observa e ressignifica o Serviço Social e a realidade latinoiberoindoafrocaribeña; do mesmo modo, dissemina suas dúvidas e autocríticas sem pretender chegar a conclusões, muito menos definitivas, o que não o impede de realizar uma crítica implacável sobre "A" reconceituação e suas vinculações com a neo-moderna ortodoxia marxista que o autor denomina brasileños et alii.

Palavras-chave: competências profissionais, "trabajosocionomía", "neoposglo", ecletismo.

\section{César A. Barrantes}

Licenciado en Trabajo Social, doctor en Estudios del Desarrollo y doctorandi en Ciencias Sociales.

Profesor investigador de la Universidad Central de Venezuela.

Presidente fundador de la Red Latinoiberoamericana y Caribeña de Trabajadores Sociales (RELATS).

\section{fó bstract}

The purpose of this article is to share a plurality of reflections inspired by the LIII Congress of the Mexican Association of Social Work Schools and is supported by the author's epistemological research. From an undeniable psychoanalytical and ethical-geopolitcal position, it focuses on non-dogmatic questions that serve as intellectual compasses, the principal of which refer to the abilities that the peoples and nations of our America are demanding of social workers. In the four sections of the article, the author presents a field of vision in which he observes and resignifies social work and the latinoiberoindoafrocaribeña reality. He also presents his self-critical doubts with no intention of reaching conclusions, much less definitive ones, this does not prevent him from conducting an implacable criticism of "The" reconceptualization and its ties with the neo-modern Marxist orthodoxy that the author denominates brasileños et alii.

Key words: professional competencies, "trabajosocionomía", "neoposglo", eclecticism. 


\section{Introduccírn}

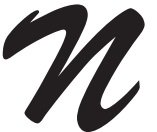
uestro trabajo se orienta, por los significantes implicados, en la convocatoria de la Asociación Mexicana de Escuelas de Trabajo Social (AMETS): "La potenciación del trabajo social en las competencias que le demanda el contexto social", la cual abre la discusión sobre los cuatro desafíos siguientes:

1. Las demandas que la realidad histórico-política le está presentando al trabajo social en nuestra América Latina.

2. El conjunto de capacidades, pericias o habilidades que hacen idóneos a los trabajadores sociales y a las trabajadoras sociales para accionar reflexivamente y reflexionar activamente sobre el desiderato al que se enfrenta toda organización social: la satisfacción de carencias y potenciación de aspiraciones de todos sus integrantes.

3. La relación entre el trabajo social realmente existente y el que nos es posible construir en el aquí y ahora que conocemos como presente.

4. La alianza estratégica entre los actores que le dan vida a los aglomerados de intereses del trabajo social. Me refiero a la integración orgánica de las personas jurídicas y naturales, en especial los sociólogos, sicólogos, antropólogos, filósofos, administradores, etc. que son parte orgánica del proceso formativo y, por ello, están implicados en la potenciación de las competencias que se les están demandando a los trabajadores sociales de cara al siglo veintiuno.

Somos competentes o no somos competentes. Es la cuestión que está puesta en escena: el desafío a nuestras capacidades innovadoras, entendiendo que las competencias tienen diversos niveles de realización: el de la instrumentalidad propia del hacer-haciendo en el mundo de los objetos tal cuales, es decir, el ámbito propio del trabajo y la relación hombrenaturaleza, de la producción y la razón administrativa mediosfines. Pero también y fundamentalmente en la esfera de la razón práctica en la cual incluimos los planos metodológico, teórico-epistemológico, jurídico-institucional, ético-estético, geopolítico, comunicacional y recreacional.

Hemos sido convocados a problematizar la oferta y la demanda social de competencias en el aquí y ahora de la era que conocemos como imperio, globalización, posmodernidad y sociedad del conocimiento entre muchos nombres, lo cual nos coloca frente a una pluriversidad de opciones planteadas no sólo desde la posición del poder académico y disciplinario sino también desde la condición de subordinación y explotación de amplios agrupamientos sociales que continúan sujetos a los servicios burocráticamente organizados, dentro de los cuales los agentes del trabajo social y otras profesiones realizan funciones esenciales; pero fundamentalmente son planteadas desde la geopolítica implicada en las nuevas formas de realización del trabajo social que, con sentido societal, vienen desarrollando amplias multitudes a las que diversos grupos de colegas e intelectuales acostumbrados al aire acondicionado, parece que tienen poco que aportar.

He aquí el fundamento ético de la convocatoria de las AMETS, entendiendo que la ética (SAVATER, 1988, p. 4647) trata, no de lo que debemos o podemos, sino de lo que queremos a partir de lo que somos. Querer ser a partir de lo que se es tiene como condición de posibilidad la libertad de exploración, de saber, de conocer cada cual por sus propios pies, caminando caminos, inventando itinerarios en cartogramas inéditos, colocar cada enfoque o visión de mundo y de vida de cualquier persona en perspectiva de totalidad, en la perspectiva de la justificación universal del sentido de la acción y de la libertad racional. La ética trata de la libertad de explorar el aquí y ahora, trata de la apropiación de los mundos de vida donde establecemos costumbres, hábitos y conductas; trata del querer aprehender los trazos demarcados por la raíz, el sentido, los límites y posibilidades de nuestra razón de ser, pero también la ética trata del querer saber lo que nos sucederá cuando rebasemos la frontera venciendo el miedo a la libertad.

Nuestra comunicación consta de cuatro apartados. Primero, caracterizamos el actual sistema imperial de relaciones de poder respecto del cual adquiere sentido la refundación del trabajo social, que vinculamos a la geopolítica de la producción de conocimientos y saberes, y a la crítica al poder neocolonial y a la colonialidad del poder. Segundo, reflexionamos acerca de los retos del trabajo social, retomando nuestra crítica a una expresión de $L a$ reconceptualización del servicio social: la marxista ortodoxa y dogmática. Los dos últimos apartados están dedicados a la crítica del discurso brasileños et alii, cuyo racionalismo crítico no autocrítico desmedra la razón sensible y la imaginación creadora.

En coherencia con el sentido abductivo de nuestra comunicación, al final no aportamos conclusiones, mucho menos definitivas. Nuestras in-conclusiones están diseminadas bajo la forma de preguntas generadoras a lo largo del texto que, por ello mismo, se inscribe en la humildad de un punto de partida cuyo ojo del huracán es el equívoco y la incompletud. Por eso no es el único ni mucho menos el mejor, sólo es uno posible, ojalá creíble, esperando que sea de alguna utilidad al menos para alimentar el afán innovador del lector.

Dada la estricta limitación del espacio asignado, hemos reducido al mínimo las citas y referencias bibliográficas sin que, por ello, la consistencia y comprensión del texto se vean afectadas.

Hoy, a inicios del siglo veintiuno, es una visión generalizada que el sistema mundial de relaciones sociales de po- 
der viene perfilando, con rasgos cada vez más definidos que hace unos decenios, una nueva era referida a la práctica de la reorganización del planeta, de las relaciones internacionales y de la producción misma de la vida social. Este sistema relacional -su naturaleza y sus consecuenciasviene siendo denominado de muy diferentes maneras, no todas coincidentes política, cultural y académicamente: globalización económica, globalización cultural, neoliberalismo, poscapitalismo, imperio, imperialismo neomercantilista, posmodernidad, sistema-mundo moderno, sistema mundo posmoderno/poscolonial, sociedad de la información, sociedad del conocimiento, sociedad en red, sociedad del riesgo, modernidad reflexiva, modernidad líquida, sociedad del espectáculo, la era de los medios, la era de la imagen, la era del vacío, la era de la euforia, la era de la diversión, etc ${ }^{2}$. Se trata de una pluriversidad de conceptos, términos, nociones y metáforas que tomamos apenas como ventanas a través de las cuales metemos nuestra cabeza en dimensiones que deben ser puestas en perspectiva de totalidad, es decir, bajo una óptica epistemológica que nos permita delimitar nuestros propios campos de observación, organizar el razonamiento analítico y reconocer en el proceso mismo de construcción de nuestra propia mirada, las articulaciones mediante las cuales los hechos humanos adquieren significaciones singular-universales.

Si tiene sentido la expresión, de innegable sentido antipositivista, de Werner Heisenberg, Premio Nobel de Física en 1932, de que la ciencia no es una sola mirada, sino que hay otras muchas, cabe preguntarnos ¿cuál es la mirada del trabajo social?, ¿desde dónde mira el trabajo social si es que mira?, mejor dicho, ¿cuál es la representación que los trabajadores sociales y las trabajadoras sociales construyen del mundo en que vivimos?, ¿desde dónde nos representamos el trabajo social y la realidad de la que somos productores y producto?, ¿desde dónde se construye la mirada del Otro que nos mira?, ¿desde dónde somos constituidos por la mirada del Otro?, ¿cuáles son los lugares de encuentro de estas miradas que pudieran psicoanalíticamente provenir de un ojo ciego?

Se trata de preguntas generadoras que admiten la exploración de múltiples vías de entrada al análisis, comprensión, descripción, explicación, predicción e intervención de los trabajadores sociales en cada instancia, dimensión, espesor, estructura o nivel de la sociedad en que nos desempeñamos y para los cuales no existen determinaciones, mediaciones ni explicaciones preestablecidas. No nos detendremos en estos escenarios. Pero parece ser una visión más o menos compartida por amplios sectores humanos, de que cualquiera sea la ventanilla por la que nos asomemos alcanzamos a ver, oír, oler y palpar imágenes sensoriales y racionales más o menos definitorias de la nueva cartografía mundial.

A este último respecto retomamos la observación según la cual las asimetrías en las relaciones internacionales e intranacionales son asumidas como una natural división del trabajo (BARRANTES, 2005): al norte le corresponde producir e innovar y al sur consumir y difundir. Una expresión de esta situación es el hecho de que las publicaciones científicas de los países del sur, específicamente de nuestra América Latina, se ven cada vez más excluidas de los índices internacionales establecidos por los centros académicos del norte. Entre las causas existentes se mencionan, por un lado, el carácter progresivamente ultraselectivo de los criterios aplicados para su inclusión en las bases de datos de los centros académicos internacionales, pero por otro lado, el bajo potencial científico de la región, la insuficiencia de las políticas de desarrollo científico-tecnológico y de innovación social, la carencia de directorios actualizados de revistas y obras universitarias, el desconocimiento del verdadero volumen de las publicaciones y más aún de la productividad de nuestras universidades dentro de las que se encuentran las escuelas y facultades de trabajo social.

Reiteramos pues, nuestro llamado (BARRANTES, 2000, 2004, 2005b, 2005c) a los organismos académicos, estudiantiles y gremiales a potenciar: 1) la discusión abierta del problema de la constitución de un pensamiento y una práctica de un trabajo social que derive en trabajosocialogía, trabajosocionomía, trabajosociodoxa, trabajosociofrónesis ${ }^{3}$, en ética-estética-geopolítica de la producción de conocimientos y saberes así como en crítica al poder neocolonial y a la neocolonialidad del poder (QUIJANO, 1998; LANDER, 1998; MIGNOLO, 2001); asimismo, 2) la construcción de identidades en y de la América poscolonial que no es el norte geográfico pero sí es el SUR que se está construyendo, si bien ontoepistémico-hermenéuticamente, fundamentalmente dóxica y fronéticamente, algunas de cuyas características más relevantes son el mestizaje, la multietnicidad, la multiculturalidad, la hibridación cultural, temas que hoy están siendo problematizados desde lugares que el poder imperial juzga como no lugares o lugares fuera de lugar (AUGÉ, 1996).

En trabajo social el neocolonialismo endogenizado por la colonialidad del poder tiene su traducción en la práctica del modo tecnoburocrático de organizar y gerenciar las relaciones de subordinación que ejercemos sobre nuestros propios colegas, especialmente entre estamentos directivos y colectivos cautivos en una diversidad de entidades, especialmente gremiales y académicas. Junto al modelo liberal, el modelo tecnoburocrático también forma parte del patrón eurocéntrico que se ha venido constituyendo como racionalidad instrumental, a la que son reducidas las relaciones de conocimiento con el mundo que nos ha tocado vivir. Sin embargo, al igual que en los ámbitos de realización de los intercambios globales, en el trabajo social estamos observando también resplandores de protagonismo democrático, de pluralidad y alternatividad respecto del patrón gerencial y cultural, hoy imperializado.

He aquí uno de los desafíos que se deriva de la demanda social de competencias a los y las agentes del trabajo 
social y cuya aceptación significaría un salto cualitativo de gran valor ético, político, social e institucional: hacer del protagonismo democrático, del estado de derecho y de justicia, soles plenos que nos iluminen el entendimiento y alimenten la práctica de un nuevo concepto de organización que implica la aceptación del hecho histórico real de un inédito corrimiento de plataformas societales respecto del cual el trabajo social no puede quedar incólume.

\section{2}

En este apartado, reflexionamos acerca de los desafíos que están interpelando a los trabajadores sociales. Para ello abordamos brevemente las condiciones sistémicas en las que se inscribe su demanda socio-institucional.

Es casi un lugar común que el trabajo social en el mundo angloeuroestadounidense se configuró como profesión en el proceso de la larga crisis de los estados liberales y su posterior reconstitución en estados intervencionistas o de bienestar social. También es sabido que, con diversos matices propios de la especificidad de cada país, en América Latina resulta ser paradigmática la historia de la demanda del funcionariado que primeramente se conoció como visitadoras y servidoras sociales, seguidamente asistentes sociales y posteriormente trabajadoras sociales. Así, desde 1925, año de la creación de la primera escuela de servicio social en Chile, hasta los años 50, la institucionalización del trabajo social estuvo directamente ligada a la crisis del modelo agroexportador y de los estados oligárquico-terratenientes, en especial cuando a éstos les llegaba - progresiva o abruptamente - el momento de modernizarse e intervenir activamente en la economía y en lo social, en la problemática social o cuestión social; en esta última, a través de la profesionalización y fortalecimiento de las fuerzas armadas y de las políticas asistenciales reactivas a las demandas socioeconómicas de las clases asalariadas y no asalariadas.

Una vez reconstituidos los estados oligárquicos y posoligárquicos en modernos estados desarrollistas de factura cepalina, el trabajo social quedó articulado orgánicamente a la práctica estadocéntrica del asistencialismo y bienestarismo populista y la modernidad dependiente que se legitimó a partir de los años 60 , constituyéndose a los trabajadores sociales en intermediadores - apa- rentemente exclusivos - de las relaciones de las agencias oficiales de política social con la creciente población excluida de los frutos del crecimiento económico. Hoy, la relación del trabajo social con el estadocentrismo desarrollista, asistencialista y populista, se ha visto afectada y reconfigurada por el intento neoliberal de construir sociedades mercadocéntricas y estadofóbicas; asimismo, por la crisis de (pos)modernidad, el desmantelamiento de los estados, los impactos perversos de la megadeuda externa y los procesos de desestructuración y fragmentación de nuestros países.

Si esta última afirmación es cierta, adquieren sentido las preguntas siguientes: ¿qué pasa con el trabajo social que se institucionalizó al alero del moderno estado si éste ya no es (quizás nunca lo fue) lo que quiso ser?, ¿determina la crisis de ese estado algún tipo de crisis en el trabajo social y sus prácticas?, ¿cómo nos representamos los ámbitos constituyentes del trabajo social?, ¿qué buscamos, cuál es nuestra ambición o aspiración?, ¿a qué tipo de poder aspiramos?, ¿a qué racionalidad, a qué problemáticas intentamos responder en la perspectiva del advenimiento de nuevas configuraciones societales ya no estadocéntricas, estadocráticas ni estadofóbicas, sino de sociedades sociocráticas de estado?, ¿podrá sobrevivir el trabajo social realmente existente, es decir, en tanto forma profesional del servicio social y de la asistencia social burocráticamente organizada desde aparatos estatales y civiles? Finalmente ¿cómo nos representamos la relación con otros profesionales que se ocupan también del proceso de satisfacción de carencias sociales que se nos ha hecho creer que es exclusivamente nuestro?

Esta última pregunta adquiere importancia porque la demanda de competencias no ha sido unidireccional en ningún país del mundo; sin negar la existencia de una demanda institucional que determinó la creación de dispositivos de formación del producto profesional que se estaba demandando desde inicios del siglo veinte latinoamericano, también es cierto que los y las agentes del trabajo social se adscribieron el perfil que asumieron como consustancial y sobre esta base empujaron la creación de su propia demanda. En este mismo sentido, cabe aclarar que la pregunta por la demanda originaria de trabajadores sociales presupone que éstos son los únicos operadores finalistas que median entre las agencias asistenciales oficiales y los agrupamientos poblacionales sujetados a los servicios producidos por éstas. Iamamoto y de 
Carvalho (1981), CELATS (1983), y Borgianni, Guerra y Montaño (2003) siguen ignorando la existencia de otras categorías laborales que, en la realidad burocráticamente organizada, también median las agencias oficiales, sus usuarios y el proceso de satisfacción de necesidades sociales y sistémicas.

No sé si existe otra disciplina que, como el trabajo social, persevere en la crítica a su razón práctica, a su razón de ser y estar en el mundo. Es posible pensar que bajo este rasgo podamos encontrar, aunque de manera media$\mathrm{da}$, ecos del estallido académico que conocemos como reconceptualización de la asistencia/servicio social, movimiento al que, entre las varias cuestiones que podemos reconocerle, dos nos parecen relevantes para los efectos de esta exposición: La primera: haber envenenado a diversos grupos de colegas y estudiantes de utopía transformadora de estructuras y deseos de construcción del hombre nuevo que, según se creía, el futuro de nuestra América Latina iba a necesitar; dentro de los límites del discurso de la universidad y de la modernidad misma, este cambio significó la búsqueda de nuevas formas de encarnar una nueva ciencia liberadora a la que, en diversos países, se comenzó a denominar trabajo social ${ }^{4}$. La segunda: haber propiciado un cambio en el dispositivo conceptual de la profesión mediante la crítica a los métodos, teorías y metateorías anteriores, aunque reduciendo la lucha epistemológica al exorcismo del pasado filantrópico-caritativo y benéfico-asistencial eclesial, liberal y conservador, lo cual se tradujo en desprecio y abandono de los métodos clásicos y auxiliares.

Contrariamente a una voz generalizada que responsabiliza a las dictaduras militares por el incumplimiento de la promesa reconceptualizadora, nuestra visión es que la problemática de dichos regímenes no exime el análisis endógeno de los límites y potencialidades de la reconceptualización misma. El cambio sistémico significado por el quiebre brutal de la democracia y la pulverización de los movimientos populares, inviabilizó la continuidad y el resurgimiento del ímpetu reconceptualizador originario que, a nuestro juicio, no contenía dentro de su propia lógica, lo que Natalio Kisnerman denominó, en una charla a la que asistí cuando era estudiante, la reconceptualización de la reconceptualización y la rerreconceptualización de la reconceptualización.

Así, mediante la brutalidad del hecho militar, la terca realidad socialmente construida demostró que, a pesar del rigor metodológico de "Los" reconceptualizados y a pesar de su fiel cumplimiento del procedimiento de la tesisantítesis-síntesis, los hechos de la vida real continúan produciéndose de manera diferente a lo pautado por la dialéctica hegeliano-marxista. La realidad societal, resistente a todo encasillamiento formalista, dejó a enormes contingentes de cientistas sociales y con ellos a numero- sos trabajadores sociales fuera de su sociológica o lógica de vida. El agotamiento abrupto y perentorio de "La" reconceptualización ya estaba inscrito en ella misma.

En consecuencia con lo anterior, ya en los 80 del siglo veinte, pero especialmente después de la denominada década perdida, en los 90, nos encontramos con la constatación - increíble aún hoy para muchos de los y las agentes del trabajo social - de que un "Gran Final" había llegado: el de los grandes proyectos, metarrelatos y promesas de la modernidad. Ante la ofensiva neoliberal y un horizonte pletórico de desesperanza e impotencia, eclosionaron los movimientos sociales y las organizaciones de la sociedad civil como contrarreferencia al movimiento y a la organización populares. Los trabajadores sociales, al igual que amplios sectores de la población, expropiados hasta de sus propios sueños, se vieron autorreferenciados a sus propios mundos de sobrevivencia y de vida ejerciendo - así fuera en su propio país o en el exilio - el trabajo social que les era posible dentro de los límites que les estaban dados: el del fragmento, la no praxis, el no discurso sistémico, el microfundamento sin macroexplicación. De allí la plétora de nuevos espacios profesionales, de nuevas demandas de servicios y competencias de los trabajadores sociales y las trabajadoras sociales, de nuevas formas de ejercer y pensar el trabajo social.

Los últimos decenios son testigos de nuevos y profundos cambios en la cartografía política, social y económica latinoamericana. Por un lado, el neoliberalismo está de capa caída en diversos países especialmente suramericanos y, por otro, los grandes conglomerados humanos que habían hecho vida en el fragmento y construido allí nuevas subjetividades y solidaridades se han visto interpelados por la nación políticamente constituida, significando nuevas articulaciones del estado, el sistema político y la sociedad civil, ahora fundadas sobre lo micro y lo local, y revolucionando los dinamismos sociopolíticos y culturales otrora desactivados por las dictaduras militares y los gobiernos neoliberales. Venezuela, Brasil, Argentina, Uruguay, Paraguay, Bolivia, la derrota del ALCA en Buenos Aires 2005, y el proyecto anticolonialista en marcha de la Alternativa Bolivariana para la América, fundamento de la integración de la Patria Grande sobre la base de la libre autodedeterminación de los pueblos, ha vuelto a poner en discusión el papel de las masas que han construido nuevos registros imaginarios, simbólicos y reales. Hoy hay nuevas subjetividades sociales y, por lo tanto, nuevas formas de hacer política, economía, cultura y, por ende, trabajo social.

Estamos en presencia de una América Latina muy distinta a la del siglo veinte y pareciera que los lenguajes de los nuevos sujetos político-culturales y algunos gobiernos apuntan más a una práctica de la ruptura con el pasado que a una ruptura con el futuro. El salto cualitativo es inédito y de tan largo alcance que la percepción generalizada es que hoy se está más cerca del aquí y ahora empiezo 
que del futuro del pasado, gracias no a la ciencia ni a las nuevas tecnologías de la información y comunicación, sino a las nuevas sensibilidades, una de cuyas expresiones es la alianza estratégica de amplio sentido multiétnico, mestizo y popular, que se ha establecido entre algunos gobiernos y amplias masas a las que se han incorporado las clases medias y fracciones de clase alta. Y estos dinamismos significan que de lo que se trata es de un corrimiento de plataformas societales con implicaciones genoestructurales en el cartograma ético-geopolítico internacional. No se trata de un salto lineal ni ascendente que se pueda ubicar en la cuadrícula cartesiana. Se trata de la construcción de nuevos puntos de partida, actuación y adueñamiento de los mundos de vida como posibilidad de advenimiento de lo que denominamos la alborada del siglo veintiuno, cuyas escenificaciones no son posibles sin los propios actores que son sus autores, tramoyistas, coreógrafos...

Nuestra percepción es que hoy, como nunca antes, parecen tener sentido tanto la intuición poética del sentimiento oceánico, atribuida por Freud a Romain Rolland, como lo que el mismo Freud alrededor de 1930 identificó como la "[...] inefable seguridad que da la sensación de inseparable pertenencia a la totalidad de un mundo mítico del cual nadie puede ya caerse" (FREUD 1975, p. 7-11); asimismo, adquiere plena significación la noción spinoziana de proyecto de inmortalidad sin el cual no habría ética, derecho ni política (SAVATER, 1988). Pero en un acto de reivindicación del pensamiento latinoamericano también me refiero a la necesidad de infinito, a la necesidad de absoluto, a la necesidad de un ideal, a las cuales se refirieron Mariátegui (1970) y Vasconcelos (1982, 1992). Éstos, interpelados por el racionalismo eurocentrista y buscando nuevos horizontes para la historia indoamericana, se refirieron al elemento movilizador de las necesidades por ellos identificadas y que hoy debemos reconcientizar y resensorializar: el mito y la capacidad fabulista e imaginativa del ser humano. Es lo que está revolucionando la fragmentación neoliberal que está siendo refragmentada y resituada en una perspectiva de totalidad que no enfoca ningún punto final, pues los pueblos y naciones parecieran estar diciendo que no quieren llegar a ningún lugar, mucho menos preestablecido, sino sólo construir y significar distintos puntos de partida que es hacia lo que nuestra América está yendo en búsqueda.

Esta condición epocal pareciera que no está siendo comprendida por algunos colegas. Así pues, desde los 70 del siglo pasado, se ha venido configurando un discurso reiterativo objeto de nuestra crítica en los dos apartados siguientes- que continúa machacando sobre los peligros que entrañan el neofilantropismo, neocaritativismo o neoasistencialismo en tanto estrategias del neoliberalismo, como si éste aún siguiera haciendo de las suyas y como si desde hace varios lustros no se estuvieran significando procesos de reconstitución sociocéntrica de los estados latinoamericanos. Característi- ca que está apuntando a estados éticos, de derecho y de justicia cuyo sujeto ya no es el cosificado de la carencia sino el sujeto de derecho, de dignidad, de reconocimiento, de aspiración, en fin, parafraseando a Savater (1988, p. 46-47), el sujeto que quiere inclaudicablemente autoafirmar su condición humana, su libre voluntad de compromiso con la realización de su deber ser mediado por las circunstancias propias de su aquí y ahora.

\section{3}

Este apartado está dedicado a la crítica - autocrítica por definición - del discurso brasileños et alii, el cual tiene su origen en las contribuciones de algunos colegas de la Pontificia Universidad Católica de San Paulo y la Universidad Federal de Río de Janeiro; denominados por unos y otros brasileños como "Los Hegemónicos” y "La Iglesia", configuran un específico campo de visión que tiene su origen en las obras de José Paulo Netto y Marilda Iamamoto - decanos eméritos del servicio social brasileño - bajo cuyo alero ideológico se siguen formando alumnos, ex alumnos, seguidores, alumnos de sus ex alumnos y seguidores de sus seguidores brasileños y no brasileños (NETTO, 1991, 1992, 2003; IAMAMOTO, 1992, 1998). Se trata de una matriz de pensamiento reiterativo que es replicada como línea de enseñanza y producción académica en Brasil y otros países y difundida por Cortez Editora, configurando así un campo expansivamente centrípeto, cuyo magneto es el modo canónico marxista de interpretación del mundo y en particular del trabajo social.

Nuestra crítica no contiene intencionalidad invalidatoria alguna del proceso formativo brasileño. No ponemos en duda su seriedad, que si bien es aducida por algunos hegemónicos como argumento de autoridad para invalidar la crítica de los críticos-autocríticos, no por ello resulta ser más seria que la seriedad de quienes realizamos un trabajo societal en, a partir y a través de la diferencia poscolonial. Tampoco descalificamos el derecho que cada cual tiene de encarnar las lecturas canónicas de Marx y de cualquier autor. Es la razón por la que nos levantamos contra el uso hegemonista que reduce el materialismo a una realpolitik y al logro de efectos Pigmalión ${ }^{5}$, lo cual consideramos incompatible con el espíritu crítico-autocrítico y ético-geopolítico del trabajo social y la producción de conocimientos y saberes.

No obstante que existen varias críticas y algún escarceo (DELLASOPPA, 2006; DI CARLO, 2004; PORZECANSKI, 2001, 2002; CORTINAS, 2003; SAN GIÁCOMO, 2004; MONTAÑO, 2001), aquí apenas reseñamos algunos puntos al discurso brasileños et alii:

Anteposición del compromiso político a las responsabilidades profesionales con los intereses del pueblo en detrimento del proceso de individualización (no 
asimilable en modo alguno al individualismo) sin el cual no hay sociedad posible ni humanismo en acto: sólo un "humanismo suspendido"(DICARLO, 2004, p.19).

El trabajo social tiene un origen espurio, en tanto religioso, en virtud de lo cual su sustancia y especificidad no deja de ser una protoforma reaccionaria que se presta, sin solución de continuidad, a los fines burgueses que se ocultan en los instrumentos que están a su servicio: los protoservicios protoasistenciales.

Descripción del desarrollo capitalista desde la óptica del hegemonismo del único actor del capitalismo monopólico: la burguesía invencible en mantener y redimensionar los mecanismos de dominación y explotación dentro de los cuales está la asistencia social.

- Develamiento de contradicciones que son borradas al ser analizadas con lógicas formales, lineales, binarias sin comprensión de la dialéctica en juego; sincretización y desvalorización del trabajo social al que se presenta como una especie inmaculada sólo parecida a sí misma y libre de contaminaciones disciplinarias que sólo conducen a eclecticismos vaciadores de su especificidad.

Culpabilización del asistente social como colaboracionista con los intereses de la burguesía, puesto que incluso las ideologías de resistencia están formuladas de acuerdo con las pautas impuestas por la lógica del capital - mercancía mediante - en nuestra propia conciencia. Todo ello motivado por la obsesión del discurso brasileños et alii, por la reproducción ineluctable de la sociedad capitalista. La queja tiene que ver menos con la evaluación de los productos cognitivos acumulados por el asistente social y más con el subestimado estatuto profesional. Nihilismo sustanciado en la desilusión respecto del socialismo real.

Proclamación de la vuelta al primer marxismo considerado el verdadero y auténtico como única vía posible de exorcizar al servicio social de su pecado original religioso, conservador, reformista, empirista y pragmatista y darle a éste una nueva identidad profesional

Las contradicciones de la crítica a la génesis y forma de profesionalización del asistente social no les permite a dichos críticos desembarazarse ni responder a los reclamos de especificidad, mejor conocimiento de la situación problemática y mejoramiento de las técnicas y efectos de la intervención profesional.

Veamos nuestra crítica-autocrítica al discurso brasileños et alii:

Con la lógica binaria exogenista-endogenista (dialéctica de la exterioridad vs. dialéctica de la interioridad) apuestan al discurso exogenista del trabajo social y desde allí se descalifica a quienes desde hace casi un siglo vienen haciendo lo mismo que Montaño (1998, p. 146), en contradicción con su principio exogenista, les pide a los asistentes sociales: pensar la realidad social desde el servicio social al cual reduce el trabajo social en tanto producto del ímpetu reconceptualizador de los años 60 del siglo pasado. Es así que, gracias a la traición del inconsciente, son los endogenistas y no los exogenistas quienes procuran cualificar cualquier especificidad, identidad y diferencia que pueda distinguir el trabajo social de otras prácticas.

Como su nombre lo indica, el exogenismo tiene su fundamento en el principio ontoantropológico de la pureza de sangre que la desesperada España del siglo XV tradujo en su defensa a ultranza, finalmente exitosa, que permitió expulsar a judíos y moros del territorio que, varios siglos después, se constituiría en la sede del gran imperio español. Como indicador del moderno hegemonismo atenta contra la sobrevivencia de las grandes multitudes y sólo permite al trabajo social y a todo ámbito de la realidad societal desde un exterior cuya locación no está mapeada en el discurso brasileños et alii, es decir, no es posible saber qué está dentro y qué afuera de qué, cuáles son sus fronteras, qué interioridad está excluida ni qué exterioridad está incluida en qué; tampoco se sabe quién sabe qué es relevante, contingente, posible ni necesario al foco temático de que se trate, el cual puede no estar donde se supone.

Lo que sí parece evidente es que el discurso brasileños et alii extranjeriza a sus actores, impidiéndoles acceder al núcleo esencial (que tampoco se sabe dónde está) de la contradicción económica fundamental del sistema capitalista. Se trata de la dialéctica de la exterioridad que le sigue atribuyendo a las dictaduras militares el precoz y abrupto agotamiento de "La" reconceptualización del servicio social con olvido de la dialéctica de la interioridad, motivo esencial por el cual las contradicciones y antagonismos estuvieron a flor de piel en las diatribas y debates entre sus más preclaros exponentes. Polémica que, habiendo sido instaurada en la creación misma de la Asociación Latino Americana de Escuelas de Trabajo Social (ALAETS), excluyó de este organismo a centenas de colegas hasta el día de hoy.

Ahora bien, si consideramos que el mundo contiene en sí mismo la génesis de su propia extinción, entonces ¿a qué agente exógeno, mejor dicho, a qué chivo expiatorio le podemos achacar el proceso de corrupción de valores y horizontes que condujo a ALAETS-CELATS a su bancarrota ética, intelectual, política, jurídica y financiera (ALAETS 2001, 2002; ARTEAGA, 2002; BARRANTES, 2002), cuyas causas se encuentran en su acta constitutiva misma y frente a lo cual el discurso brasileños et alii se ha constituido en el dispositivo legitimador de tales estructuras de poder? Es la razón por la que reitero una vez más, que la demonización y absolutización como recurso retórico aplicado no sólo a la globalización sino a todo objeto y sujeto que es visualizado como oponente, sólo puede dejarnos 
anclados en la repetición de formas de pensamiento automático que bloquean el desarrollo del trabajo social tanto como de las competencias gnoseológicas de los trabajadores sociales y las trabajadoras sociales.

Recapitulemos algunas ideas sobre el dualismo exogenismo/endogenismo:

Los exogenistas o dialécticos de la exterioridad se reputan como los únicos portadores del servicio social crítico frente a los endogenistas o dialécticos de la interioridad, a quienes se les etiqueta de ser los portadores del trabajo social acrítico no obstante lo cual, como dice Montaño (1998, p.106), estudian críticamente el "método propio,... la práctica específica (y) la teoría instrumental" del servicio social. ¿Qué estudian entonces los exogenistas: los métodos ajenos, las prácticas inespecíficas o genéricas, las teorías abstractas del no-trabajo social, del trabajo no-social, del antitrabajo social?

El discurso brasileños et alii se muestra contradictorio al presentar un endogenismo bueno y otro malo. El malo es el que encarnan los colegas estudiosos del método propio, de la práctica específica y de la teoría del trabajo social. El bueno es el de la globalización, cuyo auge incontestable se debe a que ésta ostenta una dinámica inmanente de tipo económico que conduce a la ineluctable subordinación de los hegemonizados. La economía finalmente sustituye a la política y desbarata el escenario mundial y las relaciones sociales sólo para reconfigurarlos y rearticularlos con la globalización neoliberal.

Al no poder aportar soluciones al sistema de dominación y explotación de la moderna burguesía, hoy financieramente supertrasnacionalizada, lo que se deriva es una opción indiferenciada que bien pudiera desembocar, tanto en un neosistema de dominación burguesa milenarista como - espíritus de Rudolf Hilferding y Rosa Luxemburgo mediante - en la catástrofe final y el fin de la historia. Pero también pudiera conducir a una alternativa que el discurso brasileños et alii desconcientiza: la sociedad socialista. Al no ver qué hay más allá de la imagen horizonte, invisibilizan los límites de la globalización con la consecuencia de su absolutización.

Se trata de un discurso ribeteado de pesimismo, apocalipticismo y neomilenarismo que, contrariamente a la sentencia pitagórica de que "Los hombres consiguen su más alto grado de virtud cada vez que se rinden ante los dioses" (MILLER, 2003, p. 6) su capitulación frente a la globalización no sólo resulta ser total, sino un suicidio que deja intacta la muy buena salud de que goza desde hace varios siglos la naturalización u ontologización de lo siguiente: la modernidad, la sociedad liberal de mercado, la visión teleológica de la historia universal eurocéntrica asociada a la idea de progreso lineal y ascendente, la objetividad como argumento para obligar y la superioridad de la ciencia positivista, legitimadora de la modernidad, sobre cualquier otro conocimiento.

Hasta aquí la crítica a un campo de visión hegemonista y exogenicista del trabajo social y la realidad latinoamericana, cuya base de conocimiento es el objetivamente producido y sólo captado por la razón, es decir, se trata de un discurso descorporeizado, desespiritualizado, descontextualizado, desubjetivado y tan universalmente eurocéntrico y occidentalista como lo es el pensamiento de Marx y sus fuentes de abrevadero. Y sólo teniendo en consideración estas características parece ser posible comprender por qué el discurso brasileños et alii persiste en señalar los peligros que entraña la práctica del neofilantropismo o neoasistencialismo como estrategia del neoliberalismo, como si aún éste siguiera campeando libremente haciendo de las suyas al igual que lo hizo en las décadas pasadas y como si varios gobiernos suramericanos no ostentaran el sello antineoliberal y no estén significando procesos de reconstitución sociocéntrica de sus respectivos estados.

Desconozco si hoy existe un país que se vea expresado en la imagen que desde hace treinta años reitera el discurso brasileños et alii. Es posible que si pudiéramos obtener imaginariamente videos satelitales de nuestros países, algunos develarían quantas de neoliberalismo, pero de allí a afirmar que éste sigue campeando de la misma manera que en el siglo pasado, no parece ser una realidad verosímil.

Con toda la fraternidad que me merece el discurso brasileños et alii, creo que la persistencia de su alarma obedece más a su propia lógica que a la realidad misma. Es comprensible sentir malestar por una política de estado que propone privatizar y volver al pasado histórico cuando la filantropía, la ayuda, la caridad, la beneficencia y la asistencia social estaban hegemonizadas por curas, pastores, laicos militantes del voluntariado social y otros que, seguramente, ganaron indulgencias con escapularios ajenos. ¿Cómo no atemorizarse por una amenaza tan repudiable si el origen del servicio social ha sido acusado de espurio, manipulador, estigmatizante y rutinero para decir lo menos? Sería el peor castigo para la propia lengua tener que retornar al lugar que más se desprecia.

Pero bueno, si la filantropización, la asistencialización, la beneficencialización no fueron ni son ineluctables, su reiteración como la única posibilidad que está planteada para el siglo veintiuno, puede estar significando la existencia de un objeto de deseo que, si alguna vez se tuvo, se perdió para siempre: la construcción del socialismo de cara ya no a los siglos diecinueve y veinte sino al siglo veintiuno. Es la razón por la que - como ya quedó dicho - los cambios de nuestra América, no están siendo comprendidos por quienes asimilan eclécticamente neoliberalismo a posmodernidad y neoconservadurismo y éstas a globalización. A este collage terminológico lo denominamos neoposglo (condensación de los prefijos de los términos anteriores), el cual está acechando a la vuelta de cada esquina. Inexorablemente todo paso 
adelante desemboca en ese túnel atemporal cuyo inicio es el fin de las ideologías y de la modernidad. De lo que se trata entonces es de salvar al trabajo social latinoamericano de este destino holocáustico. De allí que Borgianni, Guerra y Montaño (2003), Molina (2004) y Ruiz (2005) propongan el autodenominado proyecto éticopolítico hegemónico para los y las colegas decididamente antineoposglos que quieran ser hegemonizados por el discurso brasileños et alii.

Ahora bien, ¿cómo se puede llegar a creer que el próximo paso de la historia conduce al neoposglo y por lo tanto se quiera evitar el desemboque de los trabajadores sociales y las trabajadoras sociales en la última fase de desarrollo del capitalismo cuyo indicador es el fin de la historia y de la dialéctica? Sencillamente pensando eclecticistamente y configurando un curioso pasticho noseológico, ontológico, teleológico, enteléquico, evolucionista y dialéctico materialista e idealista.

Para este singular discurso, el mundo, la naturaleza, tienen un origen esencial que evoluciona por etapas, cada una cambiando la forma pero manteniendo como fundamento la sustancia pura; cada etapa linealmente es sucedida - mediante saltos cualitativos naturales pero no siempre necesarios - por otra superior y así progresivamente hasta llegar al final preestablecido como estadio positivo. Es decir, se trata de un proceso inexorable que va de lo más simple posible a lo más perfecto imaginable. Por otro lado pero dentro de la misma lógica, la dialéctica evolucionista, en coincidencia con el idealismo alemán, postula un punto de partida metafísico en tanto absoluto (el génesis, la primera y última instancia, el juicio final) y procediendo derivativamente propone que las etapas inferiores son sucedidas por las superiores, siempre en la línea del progreso científico-tecnológico.

El teleologismo abstracto, que absolutiza la unidireccionalidad del progresismo que conduce irremediablemente al fin último contenido en la génesis misma del mundo y del universo, eternamente perfectibles, tiene como correlato uno operativo según el cual la racionalidad instrumental está detrás de todo acto humano: la acción está naturalmente subordinada a la razón, el comportamiento se dirige ineluctablemente hacia fines, objetivos y metas determinados, eligiendo para su logro los medios más racionales. Es lo que instintivamente hicieron nuestros ancestrales homínidos de quienes somos sus más decantados productos histórico-naturales. Es lo que pareciera querer decir Guerra (2003, p. 177-178) cuando afirma -sin explicar si los fines justifican los medios y si el costo justifica la ganancia- que "Son las finalidades (las) que determinan el modo de actuar y la elección por alternativas [...] Toda postura teleológica encierra instrumentalidad." No obstante la brevedad de esta afirmación, encontramos en ella una riqueza que pareciera estar menos en lo que expresa a la letra que en lo que deja sin explicar (¿existe moral en la naturaleza?). Ello nos lleva a evocar a Locke, quien adjudicó una moral divina al Estado de
Naturaleza, y a Hobbes, quien supuso que esa moral emerge en el Estado de Derecho, sólo para poder preguntar dónde colocan el origen de la moral y la ética (distinción que pudiera parecer irrelevante en estos tiempo de neoposglo) los portadores del moderno pensamiento teleológico y enteléquico, ¿la colocan en el hombre, en la sociedad, en la naturaleza, en el instinto o en la libido? La respuesta por la que nos inclinamos es la de Elkin (2004): los quanta de constancia del instinto y la libido hacen reconocible la ética bajo la forma del deseo que Freud recorta del principio de realidad, es decir, del campo mismo de la praxis.

No sé si Guerra se ha planteado las preguntas anteriores y sobre la lucha emocional entre instintos y libido en el marco de la realidad histórica concreta. Pero parece haber superado el materialismo naturalista e idealista al desprenderse de la razón de la naturaleza en favor de la razón intelectual, racional, que el discurso teleológico y enteléquico reputa tan natural como la naturaleza misma. Sin embargo, a este respecto nos parece pertinente señalar que el desplazamiento de la razón de la naturaleza a la razón intelectual, no es condición para desintrincar el pase del orden natural de la horda primitiva a la civilización ni el consecuente alcance o acceso a las leyes o instituciones a través de la vida material de sus miembros (CARPINACCI, 2004).

En ciencias del desarrollo y de gobierno este modelo ideal, al igual que el de la mano invisible del mercado, dio origen a la noción equívoca del superhombre planificador. En oposición Gramsci se refirió a la ley física de que todo sistema tiene su propio principio óptimo de proporciones definidas (OZSLAK, 1980), significando con ello que las partes de una actividad humana organizada sólo pueden combinarse en proporciones fijas pero mediando cambiantes correlaciones de fuerza, con lo cual su concepto de bloque histórico resultó ser - a misma historia así lo mostró no a pesar de Gramsci sino a su propósito ni sólido ni homogéneo.

\section{4}

Hemos señalado que el discurso brasileños et alii procura evitar el destino teleológico y el desemboque irremediable en el neoposglo. Para ello al igual que Habermas (1983) propone recuperar, reformar y revitalizar la modernidad, es decir, el capitalismo, que no ha muerto y no está por morir; sólo se trata de un proyecto incompleto cuya crisis es apenas reconocida, como un punto de inflexión que forma parte de su propia dinámica.

Así es que para este singular discurso, toda crítica a la modernidad le hace el juego al neoposglo (como si aquélla no fuera éste y viceversa). Se trata de un recule histórico que conlleva la propuesta de revisitar y recuperar el texto de "La" reconceptualización y, por ende, su contexto: el segundo redespliegue industrial del capitalismo con los 
cuales pareciera que comienza y termina la modernidad en el trabajo social y América Latina. Es así que ya podemos leer al revés al poeta Jorge Santayana, invirtiendo el sentido -que no compartimos - de su memorable "Quem esquece o seu passado corre o risco de repeti-lo" de la siguiente manera: la mejor forma de no olvidar el pasado es repetirlo, o mejor, revisitarlo y, más aún, quedarse viviendo en él. Es la propuesta del discurso brasileños et alii: recuperar la modernidad en la que se instauró la reconceptualización, restaurarla como presente para no olvidarla, como si los protagonistas de dicho movimiento de tendencias no hubieran cambiado sus ideas y no hubieran remozado algunos de sus planteamientos en el transcurso de los últimos 40 años.

En el discurso brasileños et alii definitivamente no hay duda: el camino de ida es el mismo que el de vuelta. El tiempo que progresa es el mismo que retroactúa. El futuro está inscrito en el pasado y éste es la marca del futuro. El camino al progreso es el mismo que el de retroceso. El de la evolución al de la involución. El de la proacción a la retroacción. El de la revolución a la contrarrevolución y para atrás el regressus ad infinitum, la involución y la nada. Al fin y al cabo "sólo los ríos no se devuelven", solía decir Ricardo Jiménez, un eminente político liberal tres veces presidente de los costarricenses durante el primer tercio del siglo veinte. Y a este respecto el discurso brasileños et alii se torna políticamente correcto en tanto cálculo voluntarista: se niega a aceptar el desemboque en el neoposglo tanto como a regresar al origen del liberalismo que es el mismo del servicio social; sólo quiere retrotraerse -realpolitik mediante- a las circunstancias que le proporcionan seguridad de alguna sobrevivencia: la matriz tempo-espacial significante de la denominada reconceptualización del servicio social.

La enseñanza obtenida del discurso que nos ocupa es que la recta no existe; sólo la curva, es decir, en realidad la recta es una curva cuyos dos extremos están enchufados configurando un círculo que nunca dejará de serlo aunque algunos se empeñen en verlo cuadrado o cuadriculado. El discurso lineal, teleológico, enteléquico, evolutivo, progresivo y dialéctico no conduce al infinito ni a ningún fin último ni a ninguna perfección. Sólo conduce, como la serpiente que se muerde la cola, a la infinita circularidad, al eterno retorno, a la eterna fuga tanto al futuro pero preferiblemente al pasado. Las leyes de la economía y de la dialéctica brasileño-et-alii-zadas así lo aseguran. Debemos suponer que quienes proponen el recule histórico a los tiempos de la reconceptualización esperan, en algún momento ya pasado pero que está por repetirse, que la quiebra de la evolución que conduce al neoposglo sea el clon de la explosión académica que alguna vez se conoció como "La" reconceptualización de la protoforma que los brasileños et alii aún en 2006 siguen llamando servicio social pero que, a partir de aquel momento, es decir, en esa otra vida que los está esperando desde hace cuarenta años atrás, comenzarán posiblemente a denominar trabajo social y, quien sabe, a lo mejor trabajosocionomía de la liberación. Pues bien, cualquiera que sea la hipótesis inscrita en la estructura del discurso que nos ocupa (derrumbe o catástrofe final, tránsito evolutivo, neomilenarismo, etc.), allí mismo estarán ellos esperando muy atentos y equipados con todo el instrumental de la razón y apoyados de forma ontologista por los teóricos y filósofos materialistas de los cuales, al decir de los colegas light, Marx es el profeta más preclaro, para montarse exitosamente - tal como lo hizo Lenin en la Rusia zarista - en la ola revolucionaria que los conducirá hacia algún estadio, quizás neocapitalista o neomodernista, en donde podrán cumplir, con los habitantes que sobrevivan a la catástrofe o al neomilenarismo, la promesa de asociación orgánica entre razón, liberación y naturaleza.

Nos encontramos pues, ante una realidad: el discurso brasileños et alii es una propuesta conservadora y reaccionaria que tiene endogenizados los fantasmas restauracionistas que reaccionaron contra el movimiento reconceptualizador y creyeron ver la posibilidad de restaurar el servicio social en el periodo posdictaduras conosureñas. Hoy aquellos fantasmas disfrazados con ropajes neomodernizados, intentan repetir la historia del recule histórico y han dado - con la cabeza mirando hacia el pasado que nunca han perdido de vista - un insólito y recontradialéctico salto de carnero hacia un atrás disfrazado de adelante, en la dirección de la restauración de la modernidad que está a punto de perderse si el neoposglo triunfa. Toda una paradoja borromea que se postula en el nombre de una ética enclaustrada en el derecho positivo que enjuicia las conductas, prescribe los derechos y renuncias que los hegemonizados deben asumir como imperativo, estableciendo las sanciones cuya aplicación corresponde - en buena lógica policial - a los guardianes deontológicos del ejercicio profesional.

Un aspecto crucial del discurso brasileños et alii (dominante en las asambleas y seminarios de ALAETS) es el ataque invalidatorio a toda teoría o recurso epistemológico que no se encuentre dentro de la línea genealógica de Marx y Luckács y no responda a la ontología de la que estos dos autores -según se reputa- son tributarios. Así es que en su lista de herejes se encuentran, en primer lugar, quienes no sólo no piensan como ellos sino que, además, buscan y ostentan alternativas creadoras, procurando hacer del trabajo social un campo promisorio socialmente rentable y económicamente productivo; en segundo lugar, las concepciones que están detrás de las personas estigmatizadas: el positivismo, empirismo, estructural-funcionalismo, interaccionismo simbólico, psicoanálisis reducido a mero psicologismo, la psicología, la fenomenología, la teoría de las representaciones sociales, los estudios de género, étnicos, etáreos y de las áreas reputadas como funcionales al capital: el tercer sector, la economía social o popular, las 
oenegés, las microfinanzas, la empresarialidad popular, la innovación social, la administración de la justicia, la justicia de paz, la violencia familiar...

Para el discurso brasileños et alii, el marxismo ortodoxo no claudica en la resistencia a su propia metamorfosis en la que están interesadas las teorías que no le son consustanciales. De lo que se trata es de evitar que éstas puedan mezclarse con aquél y producirle preñeces indeseables. De allí que para mantener su pureza verdadera, se arremete contra el fantasma que supuestamente recorre América Latina: el eclecticismo, argumentando - Rozas Pagaza dixit - que éste es un "método que consiste en reunir - seguramente al estilo de los equipos interdisciplinarios que tomaron cuerpo a la largo de nuestra América cuando la reconceptualización del servicio social estaba en su momento estelar - lo mejor de la doctrina de varios sistemas" y cuyo "principal defecto" es la capacidad que tiene de mezclar de manera promiscuamente "indiscriminada", "modismos" sin demasiada reflexión y "sin (los) principios determinados de un punto de vista": el marxismo ortodoxo, y cuyas causas se encuentran en la "carencia de una formación teórica sólida", de una "actualización permanente" y, producto de la ignorancia supina en el i"excesivo pluralismo"!, es decir, en el ¡exceso de democracia!, que sólo desemboca en la crítica injustificada a la modernidad, sólo merecedora de ser defendida contra la etapa superior del imperialismo: el neoposglo (ROZAS PAGAZA, 2004, p. 108-110).

Para ortodoxos y sus fundamentalistas para quienes la epistemología aún no se ha autonomizado de la filosofía, el pensamiento heterodoxo, de frontera, complejo y no paradigmatizado es demonizado como eclecticismo, confucionismo teórico y producto de cualquier debilidad formativo-académica. En nuestro criterio, expresado hace veinte años (BARRANTES, 1999), el eclecticismo como recurso noseológico es real y su utilidad es tan válida como cualquier otro. Es útil y hasta básico en momentos de incipiente constitución investigativa. No es ninguna panacea como tampoco lo es la sistematización en trabajo social. Ambos recursos son condición necesaria mas no suficiente para la producción de conocimientos y saberes. Esto por cuanto estos tanto como sus campos constituyentes, deben ser onto-epistemologizados por comunidades de sabedores cuya validación noseológica excede la mera autorización burocrática a hacer tal o cual cosa o a sistematizar, conjuntar o combinar - mucho menos en plazos fijos - elementos disciplinarios, extradisciplinarios y extraparadigmáticos. La producción de conocimientos y saberes exige rigurosos criterios humano-racionales de demarcación (intercambio y contrastación) con evidentes consecuencias metodológicas y cuyo énfasis no es sólo la búsqueda de organización formalmente coherente con consignas político-ideológicas, sino, esencialmente, de plus de goce (LACAN, 2000), de agregación de valor al vínculo societal.
El eclecticismo es nocivo cuando el ecléctico se constituye en eclecticista, es decir, cuando absolutiza el medio ecléctico y lo trastoca ramplonamente en finalidad última. El eclecticista chapucero combina, yuxtapone, hace concurrir, rejunta en una especie de mejunje o sambrote verdades esclerotizadas y las presenta como "la" solución real y verdadera de los problemas de que se trate. Por eso llamamos la atención a fin de evitar el error tanto de la práctica del reboltillo, del pasticho y del todo vale que no tiene, según un dicho popular "ni arte ni ciencia"; como las posiciones puristas y esencialistas que sólo permiten realizar lecturas canónicas de la realidad y de las obras que nos sirven de abrevadero y constituir a sus autores en monumentos respecto de los cuales sólo cabe la repetición refleja de sus formas y contenidos. Para los dogmáticos y ortodoxos todo movimiento de superación, de salto cualitativo no unidireccional sino de ruptura, de lectura sintomática, de polisemia, polifonía, policromía y de síntesis plurales, es visto como atentatorio contra la virginidad de las teorías o paradigmas que se adoptan como doctrinas y verdades preconstituidas e invariantes, es decir, como dogmas. El eclecticismo es totalmente legítimo si no trata de reconciliar falsamente supuestos contradictorios.

Para quienes demonizan el eclecticismo (que puede resultar más dialéctico que el discurso brasileños et alii) no es concebible otra síntesis que no sea la resultante del procesamiento de elementos de una misma línea genealógica. No hay opciones, mucho menos alternativa; sólo variantes porque la esencia se mantiene y se defiende incluso a ultranza. De allí a la endogamia, la homosexualidad y la pureza racial y de sangre no hay más que un paso. Al fin y al cabo la dialéctica y el economicismo conducen al lugar que se considere objeto de deseo (¿el fin justifica los medios?, ¿será que la dialéctica es neutra y por lo tanto manejable al libre antojo de quien se asume propietario de esa varita mágica?). Tampoco son posibles las síntesis plurales y potenciadoras de las fuentes que nos abrevan, vengamos de donde vengamos, vayamos a donde vayamos, las cuales son procesadas y despojadas de sus escorias y reutilizadas críticamente en la búsqueda insaciable de nuevas respuestas a viejos problemas, de nuevos abordajes a viejas verdades; en fin, para acompañar a las muchedumbres de nuestra América en su aventura de construcción de futuro.

Es precisamente de lo que aquí se trata. Abrir sin reparos, miedos, prejuicios, hegemonismos ni dogmas, las preguntas que deberán ser trabajadas, como materia prima, por quienes quieren aceptar el desafío de dar rienda suelta a sus poderes creadores. Sin cartabones. Sin paradigmas. Sin regimentaciones. Pero no sin principios.

Recebido em 17.04.2006.

Aprovado em 19.06.2006. 


\section{Referencias}

ALAETS. Lima. Acta de la Asamblea General de Alaets, en 31 oct. 2001. In: archivos de RELATS < http://listas.reacciun.ve/ mailman/listinfo/relats-l $>$.

Guayaquil. Acta del III Encuentro de Escuelas de Trabajo Social de la Región Andina, en 12-13 oct. 2002. In: archivos de RELATS < http://listas.reacciun.ve/mailman/listinfo/relats-1 $>$.

ARTEAGA B. C. A los miembros de la Mesa Directiva de ALAETS. Caracas, 2002. Difundido por RELATS a solicitud del autor, presidente de Alaets 2001-2004, en <http:// listas.reacciun.ve/mailman/listinfo/relats-1>.

AUGÉ, M. Hacia una antropología de los mundos contemporáneos. Barcelona: Gedisa Editorial, 1996.

BARRANTES, C. Qué es eso que llamamos trabajo social. Revista Electrónica de Trabajo Social, Universidad de Concepción, v. 1, n. 3, dic. 1999, Chile. Disponible en <http://www2.udec.cl/ $\sim$ ssrevi/numero5/index.html $>$.

La Red Latinoamericana y Caribeña de Trabajadores Sociales. Un espacio para producir conocimientos, Conferencia Conjunta FITS-AIETS, Montreal, 29 jul. al 2 agosto, 2000. Revista Venezolana de Trabajo Social, Universidad del Zulia, Maracaibo, v. 1, n. 1, p. 137-161, 2000.

ALAETS-CELATS. Elementos para una crónica anunciada, enero, 2002. In: archivos de RELATS < http:// listas.reacciun.ve/mailman/listinfo/relats-l>.

Anotaciones para una reflexión sobre la geopolítica de la producción de conocimientos y verdades, Conferencia Conjunta FITS-AIETS, Montreal, 29 jul. al 2 agosto 2000. Revista Colombiana de Trabajo Social, Cali, n.19, p.83-97, 2005.

Trabajo social en el contexto actual ¿Reinvención o repetición? Conferencia Inaugural. In: LIII AMETS, León, Guanajuato, México 5 al 7 mayo, 2005a.

. Desafíos ¿del o al? trabajo social en tiempos de imperio, posmodenidad y globalización". In: XVIII SLETS, San José, 12-15 jul. 2004. También en Revista Regional de Trabajo Social, Montevideo, n. 33, 2005b, en línea <www.revistatrabajosocial.com/>.

Pensar el trabajo social en la construcción de un nuevo paradigma. Ponencia magistral de cierre en Congreso Ordinario de la FMETS, UNAM, México D.F. del 17 al 19 de noviembre de 2004. Revista Margen, Buenos Aires, n. 36/37, 2005c, en línea $<$ www.margen.org/>.

La innovación ¿en o del trabajo social? Ponencia al Tercer Encuentro de Escuelas de Trabajo Social de la Región Andina. Guayaquil, 11-13 de noviembre de 2002. Con el nombre de "El trabajo social en Venezuela: una mirada histórico-social". Revista Costarricense de Trabajo Social, órgano del Colegio de Trabajadores Sociales de Costa Rica, n. 16, 2004.

BORGIANNI, E.; GUERRA, Y.; MONTANO, C. (Orgs.). Servicio Social Crítico. Hacia la construcción del nuevo proyecto éticopolítico profesional. São Paulo: Cortez, 2003.

CARPINACCI, J. Sicoanálisis: identidad y transformación. Buenos Aires: Lumen, 2004.
CELATS. Trabajo Social en América Latina. Lima: Ediciones CELATS, 1983.

CORTINAS, R. Debatiendo con José Paulo Netto. Análisis crítico del libro Capitalismo Monopolista y Servicio Social. Revista Regional de Trabajo Social, Montevideo, n. 28, 2003. Disponible en $<\mathrm{http}$ ://www.revistatrabajosocial.com/sumario 28.htm>.

DELLASOPPA, E. E. XXI teses sobre a auto-denominada corrente hegemônica no serviço social. Disponible en <www.servico socialdemocratico.hpg.ig.com.br/>. Acceso en feb. 2006.

DI CARLO, E. et al. La profesión de trabajo social. Naturaleza, significado social y formas de acción profesionales. Argentina, Fundación Paidea y Universidad Nacional de Mar del Plata, tomo I, 2004.

ELKIN, M. Del trieb de Freud y del deseo del psicoanalista. Cuadernos del INES, n. 2, Edición del Centro de Investigación y Docencia del INES, Bogotá, 2004.

FREUD, S. El malestar en la cultura, Madrid: Grijalbo, 1975.

GUERRA, Y. Instrumentalidad del proceso de trabajo y servicio social. In: BORGIANI, E.; GUERRA, Y.; MONTAÑO, C. (Orgs.). Servicio Social Critico. Hacia la construcción del nuevo proyecto ético-político profesional, São Paulo: Cortez, 2003.

HABERMAS, J. La modernidad: un proyecto incompleto (1983). In: FOSTER, H. (Ed.). La posmodernidad. Barcelona: Kairos, 1998.

IAMAMOTO, M.; CARVALHO, R. de. Relacões sociais e Servico Social. Esboço de uma interpretação históricometodológica. ALAETS/CELATS, Lima, 1981.

IAMAMOTO, M. V. Renovação e conservadorismo no Serviço Social. São Paulo: Cortez, 1992,

O Serviço Social na contemporaneidade: trabalho e formação profissional. São Paulo: Cortez, 1998.

LACAN, J. Seminarios del 1 al 27 sin textos establecidos. Buenos Aires: Escuela Freudiana de Buenos Aires, versión CDRoom, 2000.

LANDER, E. Modernidad, colonialidad y posmodernidad. In: SADER, E. (Ed.) Democracia sin exclusiones ni excluidos. Caracas: Nueva Sociedad/UNESCO, 1998, p. 83-98.

MARIÁTEGUI, J. C. El alma matinal. Lima: Editorial Amauta, v. 3, 1970.

MIGNOLO, W. (Comp. e Introd.) Capitalismo y geopolitica del conocimiento: el eurocentrismo y la filosofía de la liberación en el debate intelectual contemporáneo. Buenos Aires: Ediciones del Signo, 2001.

MILLER, J. A. La orientación lacaniana (2002-2003), un esfuerzo de poesía. Mediodicho, publicación trimestral de la Escuela de la Orientación Lacaniana, Córdoba, Argentina, año 7, n. 25, p. 520, jun. 2003.

MOLINA, L. (Org.). La cuestión social y la formación profesional en trabajo social en el contexto de las nuevas relaciones de poder y la diversidad latinoamericana In: XVIII Seminario Latinoamericano de Escuelas de Trabajo Social, julio, San José, Costa Rica. Buenos Aires: Espacio Editorial, 2004. 
MONTAÑO, C. Ladran Sancho! Señal que cabalgamos. Réplica a algunos ensayistas desconcertados. Foro Surá, Universidad de Costa Rica, v. 66, 2002.

La naturaleza del Servicio Social: un ensayo sobre su génesis, su especificidad y su reproducción. São Paulo: Cortez, 1998 .

MORIN, E. Introducción al pensamiento complejo. Barcelona: Gedisa, 1994.

NETTO, J. P. Notas sobre marxismo e Serviço Social, suas relações no Brasil e a questão do seu ensino. Cadernos ABESS, n. 04, São Paulo: Cortez, 1991.

Capitalismo monopolista e Serviço Social. São Paulo: Cortez, 1992

. El Servicio Social y la tradición marxista. In: BORGIANI, E.; GUERRA, Y.; MONTAÑO, C. (Orgs.). Servicio Social Critico. Hacia la construcción del nuevo proyecto ético-político profesional. São Paulo: Cortez, 2003, p. 153-169.

OZSLAK, O. Politicas públicas y regímenes politicos: reflexiones a partir de algunas experiencias latinoamericanas. Buenos Aires: Ediciones Estudios CEDES, 1980.

PORZECANSKI, T. No cabalgan lo suficiente: réplica a una réplica dogmática. Uruguay, 2002. Disponible en $<$ http:// www.ts.ucr.ac.cr/suradoc.htm>.

Algunas cuestiones disciplinares del Trabajo Social en el Uruguay contemporáneo. In: Seminario Internacional de culminación de la Maestría en Trabajo Social, Universidad Nacional de Entre Ríos, 16-20 mayo 2001.

QUIJANO, A. La colonialidad del poder, cultura y conocimiento en América Latina. Anuario Mariateguiano, v. IX, n. 9, p. 113122, Lima, 1998

ROZAS PAGAZA, M. Tendencias teórico-epistemológicas y metodológicas en la formación profesional. In: MOLINA, L. (Org.). La cuestión social y la formación profesional en Trabajo Social en el contexto de las nuevas relaciones de poder y la diversidad latinoamericana. In: XVIII Seminario Latinoamericano de Escuelas de Trabajo Social, julio, San José, Costa Rica. Buenos Aires: Espacio Editorial, 2004, p. 108-110.

RUIZ, A. (Coord.). Búsquedas del Trabajo Social latinoamericano. Urgencias, propuestas y posibilidades. Buenos Aires: Espacio Editorial, 2005.

SANTOS, Boaventura De Sousa. Introducción a una ciencia posmoderna. Centro de Investigaciones Posdoctorales, FACES-UCV, Caracas, 1996. (Colección de Estudios Avanzados 3).

SAVATER, F. Ética como amor propio. Barcelona: Grijalbo Mondadori, 1988.

VASCONCELOS, J. La raza cósmica. Redición de 1948, México: Espasa-Calpe, 1982. (Colección Austral 802).

1992

\section{Notas}

1 Una primera versión coloquial y más amplia puede verse en Barrantes (2005a).

2 Para una bibliografía, Barrantes (2005a).

3 Con estos términos significamos no necesariamente una propuesta rebuscada de cambio de nombre del trabajo social, sino un cambio de su sentido que apunte a la búsqueda de estrategias de articulación del carácter prudente y convivencial del sentido común y la sabiduría popular con el carácter segregado y elitista de la ciencia y la universidad, fundamento de una nueva noción o concepción del trabajo social, mejor dicho, del trabajo societal. Se trata de una provocación o llamado de atención sobre la libertad que cada uno de nosotros tiene de querer asumir, más allá o más acá de los discursos de la universidad y de la ciencia, el compromiso que está implicado en la definición del trabajo social como disciplina académica, una de cuyas actividades esenciales es la producción, circulación y consumo individual y colectivo de conocimientos y saberes que siendo prácticos no dejen de ser esclarecidos y siendo sabios no dejen de estar socialmente producidos, pero, fundamentalmente, democráticamente distribuidos (SANTOS, 1996; MORIN, 1994) en el proceso mismo de creación, traducción y satisfacción de necesidades (carencias y aspiraciones) sociales (individuales y colectivas) y sistémicas (la sociedad considerada en su conjunto más inclusivo). Se trata de asumir endogénicamente el logos y la nosis, la doxa y la episteme, la mayéutica y la frónesis en las prácticas pensantes del trabajo social en la América nuestra que se está construyendo en y a partir de la diferencia poscolonial.

4 En la República Bolivariana de Venezuela, desde 1942, año de la graduación de la primera camada de trabajadoras sociales, el nombre oficial de la profesión es trabajo social y el de las personas que lo ejercen es trabajador social y trabajadora social.

5 Es el efecto de una concepción específica del poder autoritario para el cual la diferencia entre estilo, lenguaje, esencia y apariencia sólo existe si sirve para imponer, codificar, cosificar, pulverizar, descalificar, distorsionar, ocultar, manipular, disociar, violentar y agredir... Sus consecuencias nefastas en el sistema educativo y en el conjunto de las relaciones sociales son harto conocidas. Variantes del efecto Pigmaleón dan cuenta de que el prejuicio, la prepotencia, el hegemonismo, el autoritarismo, si bien deforman realidades, también las crean (como Stalin, Pinochet, la dictadura militar conosureña, Bush. En trabajo social que cada quien coloque sus ejemplos).

\section{César A. Barrantes}

cbarran@reacciun.ve

$<$ http://istas.reacciun.ve/mailman/listinfo/relats-1->

$<$ www.relats.org $>$

Universidad Central de Venezuela - UCV

Facultad de Ciencias Sociales

Ciudad Universitaria

Urbanización Los Chaguaramos

Caracas, República Bolivariana de Venezuela 